\title{
Casas Invisíveis
}

\author{
Mariana Guimarães ${ }^{1}$
}

1 Artista, educadora e pesquisadora . Doutoranda em Artes Visuais pelo PPGAV/ EBA/UFRJ. Atualmente é docente de artes visuais do CAp UFRJ. Sua pesquisa está relacionada com a investigação do fio como linguagem e dispositivo de mediação na arte contemporânea, clínica e educação em diálogo com práticas ancestrais de tessitura e seus inúmeros desdobramentos políticos, estéticos, éticos e sociais, em intersecção com a casa e a mulher. Desenvolve trabalhos e pesquisas com distintos grupos em diversos territórios. Universidade Federal do Rio de Janeiro. E-mail: marianasguimaraes@hotmail.com. ORCID: https://orcid.org/0000-0003-4009-3451. Lattes iD: http://lattes. cnpq.br/0439164546070328. Rio de Janeiro, Brasil. 
"Pela manhã ocupo-me com a cozinha e as aulas de alfabetização para minha filha. Com equilíbrio empilho as panelas molhadas em cima da tampa da máquina de lavar roupa para secarem ao sol.

- Mãe, como escreve quarentena?"

A casa é plástica, e essa maleabilidade permite reinventarmos sua condição que historicamente lhe foi atribuída como local de opressão, violência, confinamento, domesticação, trabalho produtivo e reprodutivo, sobretudo às mulheres.

Esse ensaio visual tem como objetivo apresentar um recorte da produção da artista que desenvolve suas pesquisas plásticas e teóricas em artes visuais a partir da investigação do espaço doméstico como espaço de reinvenção e criação de novos mundos em tensionamento com a sustentação do desejo de criação na mulher artista, pesquisadora, mãe, dona de casa.

Produzindo deste modo um trabalho que acontece entre a vida pública e a vida privada, e sobretudo através das brechas para a corporificação de uma poética iminente que acontece nos espaços entre o ateliê, a cozinha, a sala e o texto.

O título Casas Invisíveis faz alusão à belíssima obra de Ítalo Calvino ${ }^{1}$ que ao imaginar As Cidades Invisíveis (2017), promoveu na autora o desejo por imaginar e escrever minitextos que descrevem como seriam as casas invisíveis presentes em suas memórias.

O ensaio é tecido através do diálogo desses minitextos e frames de vídeos performances da série video doméstico (2020), onde a artista realiza pequenos registros do trabalho cotidiano na casa.

Em uma sociedade regida pela lógica patriarcal, muitas funções estereotipadas de gênero ainda não foram superadas. Ainda que em contextos diversos e muitas lutas conquistadas, as funções de servir e cuidar são ocupações atribuídas majoritariamente às mulheres. No Brasil o abismo ainda é maior e mais profundo à medida que não superamos e discutimos com o rigor necessário a iniquidade e injustiça praticada entre a casa grande, a senzala e a oca.

De modo que, a discussão sobre a casa, faz-se urgente. Revela o privado 
que é público e político, e mostra como trazer "a luta da cozinha e do quarto para as ruas." ${ }^{2}$

Neste momento, seguimos em casa, em quarentena e isolamento social, medidas adotadas pela Organização Mundial de Saúde (OMS) como modo mais eficaz de prevenção e achatamento da propagação do novo corona vírus ( Covid-19).

Seguimos trabalhando, acudindo a vida aonde se faz necessário.

Em quarentena seguimos em nossas casa, nos cuidados domésticos, trabalhando a todo momento, e em uma perspectiva mundial, a casa virou o centro do mundo.

Em casa, seguimos trabalhando para o Estado, cuidando de crianças, idosos, cozinhando, mantendo a coesão em momento de grande colapso. O trabalho não para, e a exploração da mão de obra também. Mulheres em home office trabalhando com as crianças em casa, sem redução da carga horária. Mulheres trabalhadoras domésticas seguem trabalhando arriscando seus corpos ou já desempregadas. Mulheres autônomas, ou chefes de família (37,3\% das famílias brasileiras são chefiadas por mulheres.) ${ }^{3}$ se virando para trabalhar, cozinhar, cuidar de seus filhos, cuidar de si, cumprir prazos e pagar boletos. Mulheres trabalhadoras informais e moradoras de periferias lutando para garantir o essencial: alimento, saneamento básico e saúde de um Estado violento e ausente.

Mulheres seguem cada dia mais disponíveis, desgastadas e sobrecarregadas, e ainda há o aumento significativo da violência doméstica contra muIheres e meninas nesse período de isolamento social. ${ }^{4}$

Estamos trabalhando na quarentena, estamos trabalhando a todo instante, acumulando jornadas de trabalho, dentro e fora de casa.

Entendemos que a casa é a base do crescimento do capitalismo, que segue matando e oprimindo mulheres desde então, a cada oportunidade com uma nova roupagem, esperto que é, o patrão.

2 FEDERICl, Silvia. O ponto zero da revolução: trabalho doméstico, reprodução e luta feminista. São Paulo: Elefante,2019, p. 46.

3 Fonte IBGE: https://censo2010.ibge.gov.br

4 Fonte ONU: https://nacoesunidas.org/chefe-da-onu-alerta-para-aumento-da-violencia-domestica-em-meio-a-pandemia-do-coronavirus/ 
A relação é de servidão, ainda que assalariadas, pois toda força de trabalho é dinheiro. O trabalho doméstico é uma força de trabalho construída sobre o equivocado pretexto de trabalho natural, amoroso e gratuito, valores que o capitalismo forjou e impôs para todas as mulheres.

Em tempos de quarentena, isolamento social e fim do mundo, o trabalho doméstico é trabalho exponencial.

A casa é plástica, uma instituição que nos aprisiona e pode nos libertar também. É necessário reivindicar o lugar da casa e da rua, tensionando e politizando esses lugares, não um em detrimento do outro, mas afirmando a potência de existir no entre.

A teorização e investigação do espaço doméstico nos permite cartografar lacunas, inventar memórias e sobretudo afirmar a micropolítica que reside na criação de novos modos de referência para o doméstico, sem permanecer em condição de submissão ao poder instituído, e a criar pautas para pensá-lo na macropolítica reivindicando ao Estado a implementação e regulamentação de políticas sociais e econômicas que tangem as suas questões específicas.

E seguir questionando a vida cotidiana naquilo que ela é mais potente, seu poder de produzir processos de singularização, deslizes, fugas, assumindo deste modo, radicalmente a casa como espaço de liberdade e criação de mundos outros. 

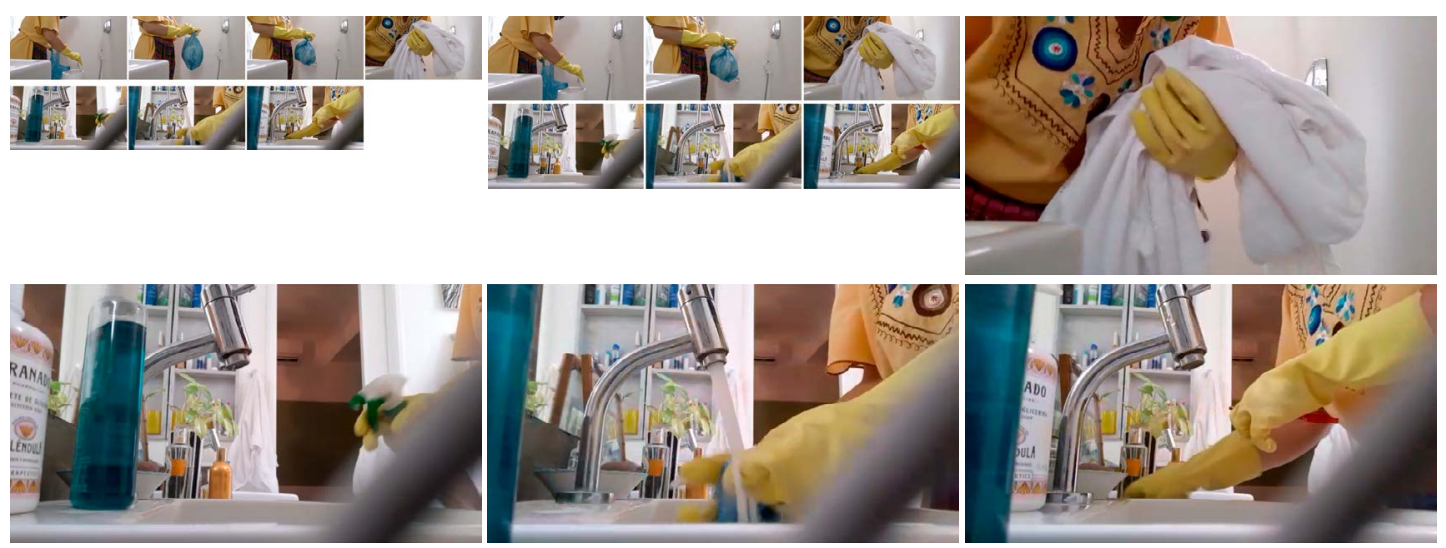

Quando lavo a louça eu faço uma cuia com a mão para juntar bastante água e lentamente vou enxaguando as vasilhas, faço também um quatro dobrando uma perna na outra.

Em equilíbrio vou esvaziando a pia. 
As gavetas da sala de jantar guardam pequenas coisas que não sei do que falam, e sempre tem um enfeite de Natal para me lembrar de não esquecer.

Soube que no quarto de casal, sob a cama, do lado esquerdo, há um buraco, como uma saída de emergência para dias de tédio.

O quarto da menina guardava uma grande bacia rosa desbotada que carregava um futuro: bonecas loiras sem roupa e um boneco amedrontado.
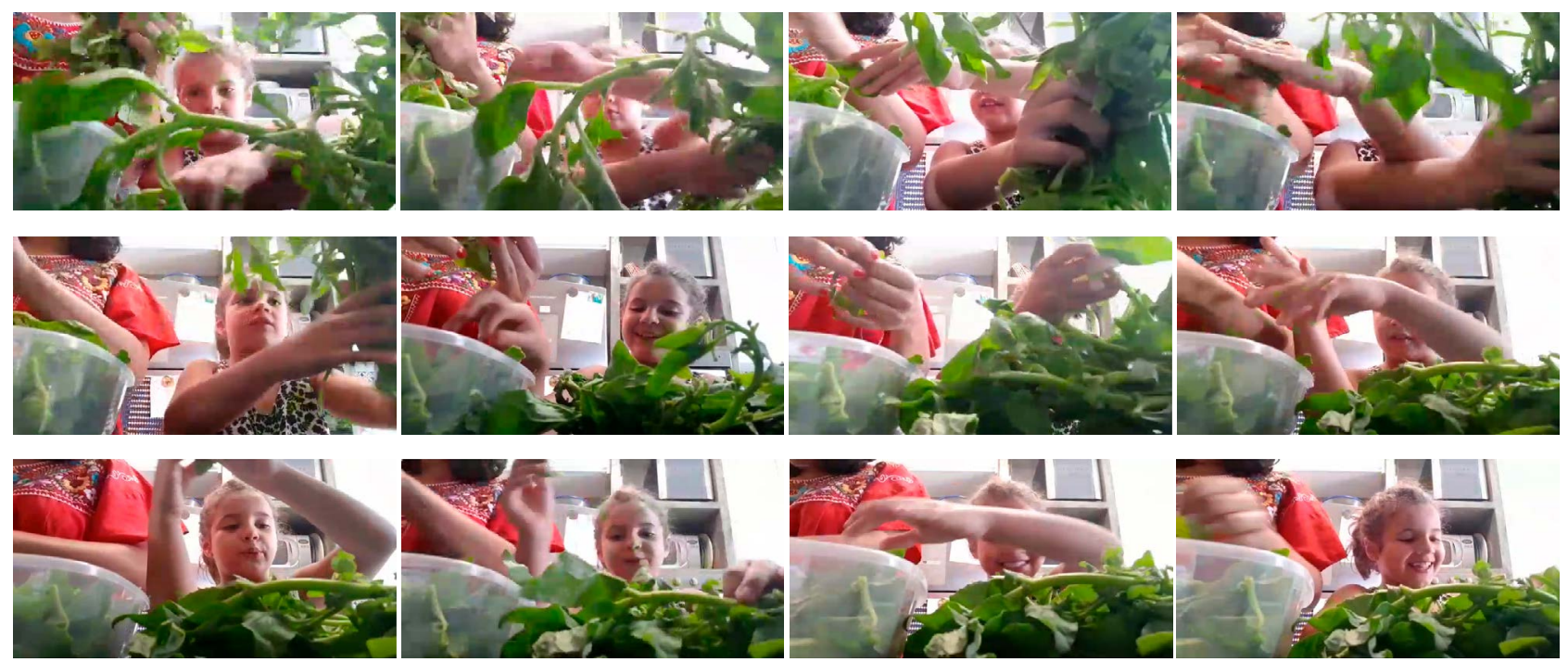
Impressionante o número de remédios vencidos no armário da cozinha. O armário é o mais estreito, mas o conteúdo é sempre profundo.

Tinham muitos tapetes no apartamento, em todos os cômodos. Era como se caminhássemos sempre nas nuvens.

Nunca entendi o Buda ao lado dos ratos de porcelana, mas sempre gostei de vê-los juntos.

O bibelô é um grande bibelô.

$\mathrm{Na}$ arca da sala, junto dos paninhos tem copinhos de licor que jamais foram usados.

No alto do barranco tem uma casa com janelas azuis, tem rancho e nossa senhora sempre passa por lá.

Não suportava a beleza dos arranjos de flores. Eram sempre de uma beleza inacessível, mesmo diante dos olhos.

Os paninhos esperam na gaveta junto com as traças.

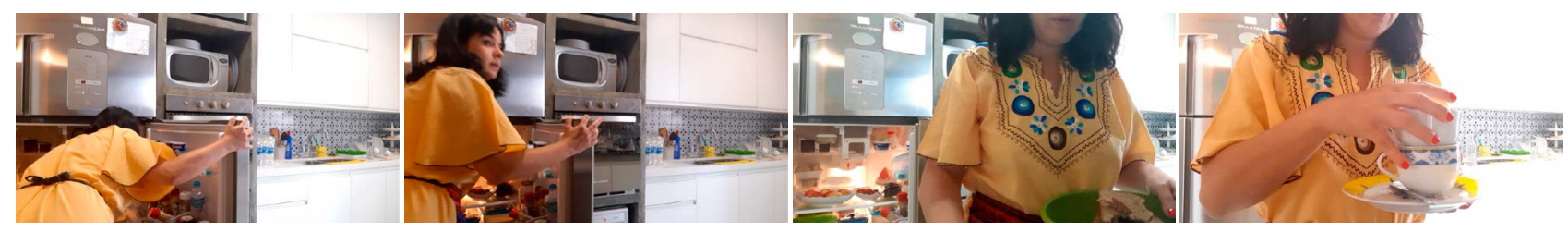

Minha avó pintava pedras, no tempo em que ela era feliz. 

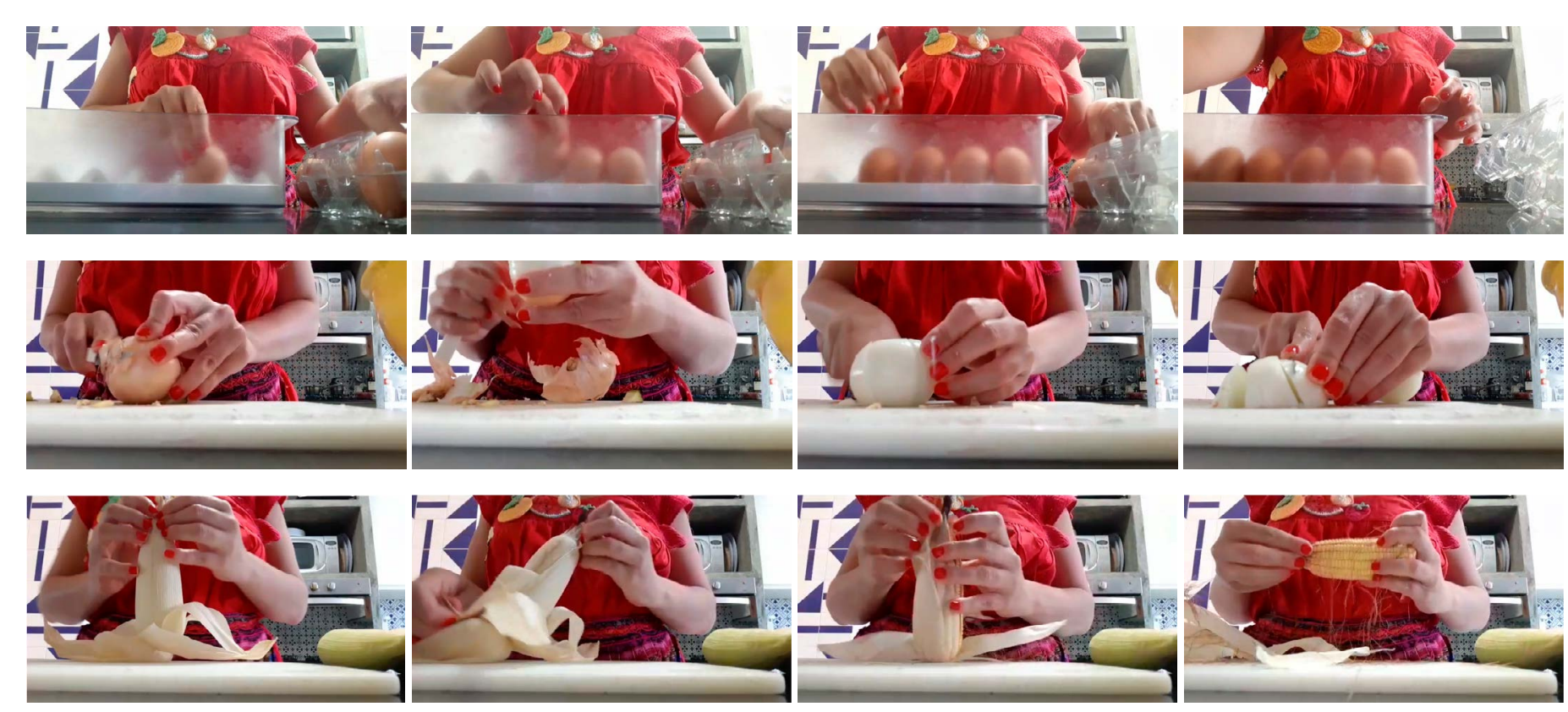

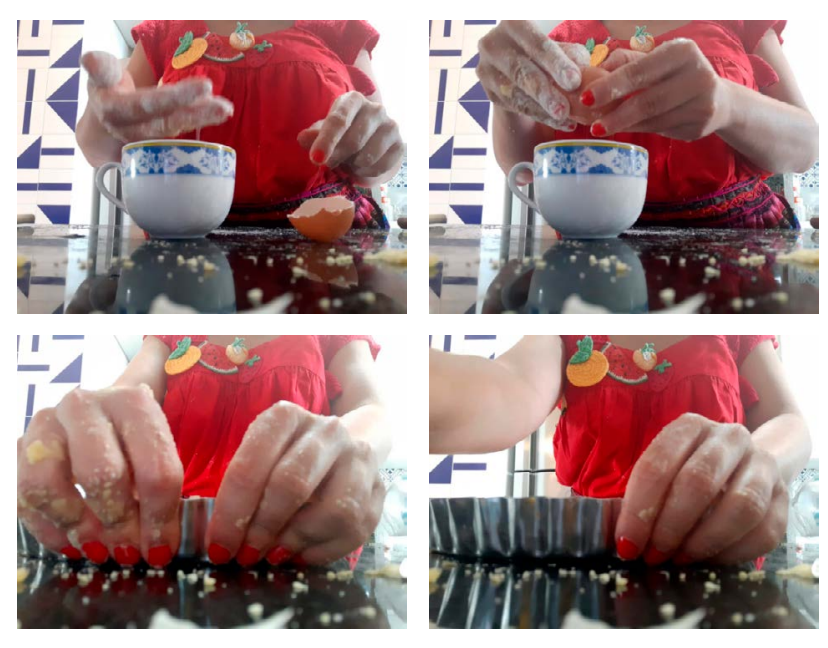

Passou um mascate e vendeu um cobre leito azul celeste com bordados de Ibitinga. A cama tem roupa de sair e de ficar em casa, mesmo que ela não saia.

$\mathrm{Na}$ época que existiam ciganos na rua, comprei no carnê, para pagar em vinte vezes uma colcha de seda toda bordada, para combinar fiz umas almofadas de crochê com linha Cléa branca, só usava em dias especiais. Mais um dia a colcha mofou. Era uma gente se capricho.

As louças na pia impõem um ritmo no caos da cozinha. Como um ritornelo.

Aliás, máquina de lavar louça é útil? 

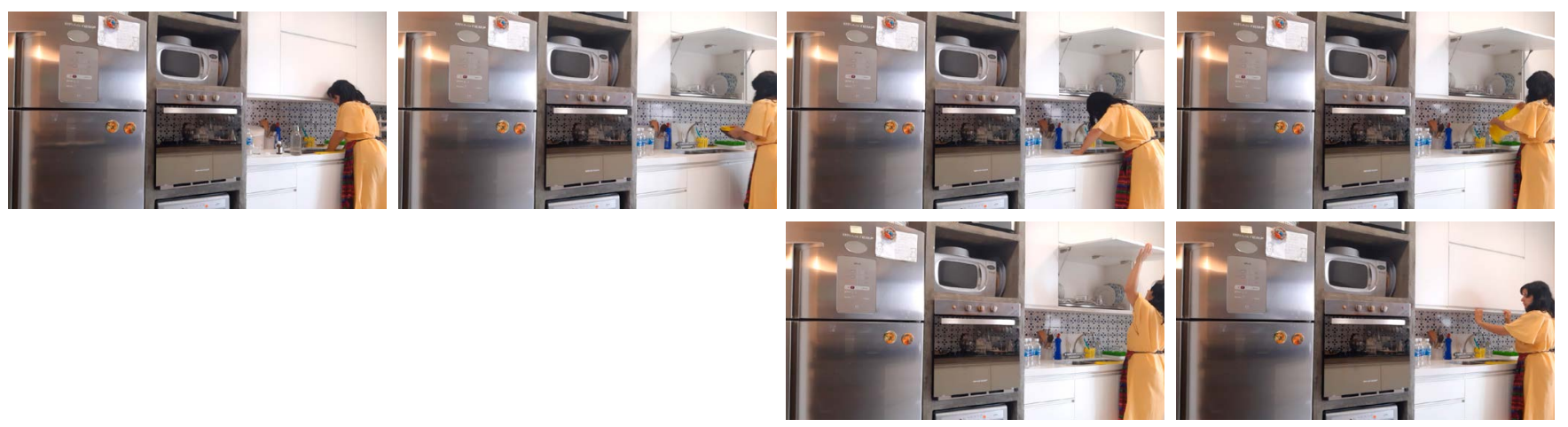

Água sanitária é o combustível da morada, clareia as manchas domésticas.

Após o almoço limpava cotidianamente com álcool 70 os armários, o fogão e as mãos. Eram medidas para não se contaminar demais. 
Tem uma pilha de potinhos de plástico no armário da cozinha, cada um será testemunha de um desencontro.

Houve um tempo em que era bonito esfregar cera vermelha no chão e deixar-se contemplar na imensidão das ondas da enceradeira.

Acho mesmo essa parte da enceradeira uma beleza.

No jardim tem uma trepadeira que se chama lágrima de Cristo. Trepa lentamente e desperta a cada primavera.

Nunca foi pecado roubar flor e colecionar latas de banha plantadas no quintal.

A toalha no banheiro úmido fedia demais, os papéis saltavam da lixeira, assim foram felizes, por um tempo. O odor impregnou-se nos corpos.

Atravessava a parede um vulto amarelo de mulher distorcida, revirada e rasgada como velhos papéis de parede que insistem em nos habitar. 

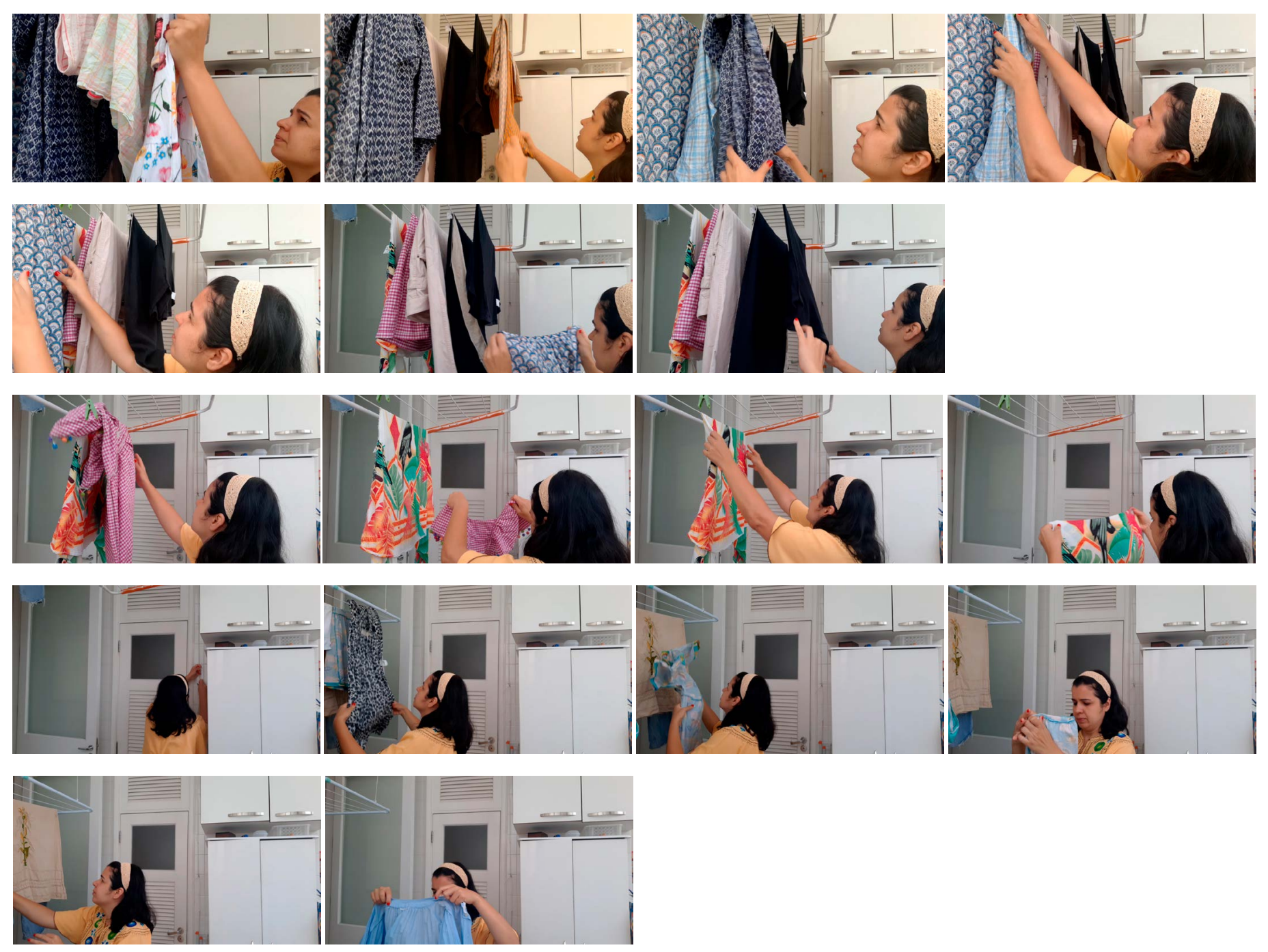

Frames da série: Vídeos domésticos. Rio de Janeiro, 2020.

Fonte: Acervo da artista.

Recebido em 18 de abril de 2020 e aceito em 04 de junho de 2020.

Este é um artigo publicado em acesso aberto sob uma licença Creative Commons $(\mathbf{c c})$ ) EY 